\title{
Institutional Review Board Training for Community Practices: Advice from the Agency for Health Care Research and Quality Practice-Based Research Network Listserv
}

\author{
Rowena J. Dolor, MD, MHS, Peter C. Smith, MD, and Anne Victoria Neale, PhD, MPH
}

Human subject protection training is required for all research personnel regardless of funding source. This article summarizes recommendations from a discussion about ethics training for community personnel from the practice-based research network (PBRN) listserv sponsored by the Agency for Health Care Research and Quality PBRN Resource Center. PBRN projects can involve community providers and their staff as subjects of the research project or as collaborators with recruitment and data collection. Distinguishing between usual care and research procedures is important for determining if training is required of community-based personnel. The use of research assistants or practice facilitators to collect research-related information is one way of limiting practice involvement to usual care procedures, thereby allowing PBRNs to limit training to dedicated research staff. Key methodologies for human subject protection training of community practice staff include on-site lectures, online modules, videotapes, and paper-based training. Ultimately, a discussion by the PBRN researcher with his or her governing Institutional Review Board is recommended for finding acceptable strategies within a PBRN. (J Am Board Fam Med 2008;21:345-352.)

New practice-based research networks (PBRNs) face a variety of operational challenges when starting projects within the community practice setting. Such challenges include hiring and training research assistants, practice recruitment, training providers and staff, determining staff availability for study procedures, finding space to conduct study interviews, and patient recruitment and retention. Compared with single-site, academicbased projects, implementation of communitybased studies requires extra planning, attention to relationships, and adaptability. ${ }^{1}$ One of the most

Submitted 5 May 2008; revised 5 May 2008; accepted 8 May 2008.

From the Division of General Internal Medicine, Duke University Medical Center (RJD), Durham, NC; the Department of Family Medicine, University of Colorado, Denver (PCS); and the Department of Family Medicine and Public Health Sciences, Wayne State University (AVN), Detroit, MI.

Funding: none.

Conflict of interest: none declared.

Corresponding author: Rowena J. Dolor, MD, MHS, Duke Primary Care Research Consortium, Box 3850, Duke University Medical Center, Durham, NC 27710 (E-mail: rowena.dolor@duke.edu). difficult operational challenges for PBRNs is ensuring appropriate yet efficient human subjects protection (HSP) for their research. Newly established network investigators and coordinators can benefit from mentoring by or networking with their more experienced counterparts in confronting these challenges.

The Agency for Health Care Research and Quality (AHRQ) PBRN listserv is a venue for communication available to registered members. Practice-based networks with at least 15 clinicians or practices and composed of more than $50 \%$ primary care clinicians are eligible to register with the AHRQ PBRN Resource Center. ${ }^{2}$ Registration is free, and the registry contains 35 questions pertaining to design, size, and geography of the network, the types of research conducted within the network, and staff contact information. Although primarily used for sending announcements to the group, individual members can pose questions or solicit advice for any issue pertaining to practicebased research. This article reports an example encountered by the Northern States Ambulatory Research Network PBRN, located in North Da- 
kota, regarding the training of community personnel on HSP. The discussion thread contains advice from experienced PBRN members and insights into the different approaches used to satisfy the Institutional Review Board (IRB) training requirement.

\section{Results}

The listserv discussion is shown in Table 1. All respondents have agreed to have their responses published and were provided the opportunity to review and edit their comments.

\section{Discussion}

PBRNs are "disruptive innovations," 3 challenging research orthodoxy and expanding the horizons of the research enterprise. PBRNs evolve to meet the nation's health care challenges as the need for sophisticated translational research grows ${ }^{4}$ and distinctions between research and quality improvement blur. ${ }^{5}$ Best practices research, clinical demonstration projects, learning collaboratives, quality improvement organizations, and regional health information exchange organizations are increasingly under the contradictory pressures of having to prove and share their effectiveness in ways that look more and more like research, and having to abide by increasingly stringent HSP regulation. The recent controversy regarding IRB oversight of a quality improvement project using intensive care unit checklists is but one highly visible example of the confusion engendered by these contradictory pressures. ${ }^{6}$ The challenge for PBRNs is to continue to create new knowledge to improve peoples' health while ensuring adequate protection of participants who are potentially at risk in this difficult environment.

The use of an electronic mail forum to pose questions and receive advice from PBRN leaders is one method of learning from the experiences of others who have faced similar dilemmas. In this example, investigators involved in the design and conduct of studies based within the community setting are required to understand the issues regarding HSP training for clinicians and staff. Investigators must understand which protocol designs require clinician HSP training, the pertinent HSP content that should be covered, permissible methods for delivering training, and specific local IRB requirements. Common themes that were dis- cussed in the AHRQ PBRN listserv are highlighted below.

\section{Does my Protocol Require HSP Training of Community Practitioners and Their Staff?}

The US Office of Human Research Protection requires that "key personnel," defined as "all individuals responsible for the design and conduct of the study," complete HSP training. ${ }^{7}$ Given the constraints of a busy primary care practice, PBRN researchers are careful to delineate the roles of everyone involved for each study protocol. Responsibilities may include recruitment, informed consent, study intervention, survey completion, follow-up, and data entry. ${ }^{8}$ In some studies, such as those in which the clinicians and staff are either the subjects of the study or are solely required to continue with procedures that are considered part of usual care, most of the research responsibilities can be conducted by a research assistant who has completed the required HSP and study procedure training. However, in some situations Health Insurance Portability and Accountability Act (HIPAA) regulations may prevent the efficient collection of data by research assistants who would not otherwise have access to patients' protected health information (PHI). However, other study protocols may require the office staff or providers to identify eligible patients, recruit these potential participants, obtain informed consent, offer the study intervention, fill out study-related forms, and conduct follow-up. Any procedures such as these that are outside the realm of usual care are considered study-related and require HSP training.

\section{Why is HSP Training Required of Community Practices?}

Participating clinicians and clinic staff require HSP training to ensure their understanding of the ethical obligations under current research regulations. There are differences between usual patient care and research. For example, asking a patient to fill out a medical history and insurance form differs from asking the same person to fill out a research survey on his or her health status, which will be analyzed with other respondent data. The former is required for clinical care and the latter is a voluntary activity. Because clinic staff are often involved in initiating contact with potential participants for a study, they must understand voluntary informed consent and how they can influence or persuade people to participate. Because 


\begin{tabular}{|c|c|c|}
\hline Inquirer Name & PBRN & Question \\
\hline $\begin{array}{l}\text { Jessica Behm } \\
\text { Date of inquiry: } \\
\text { 10/30/2007 }\end{array}$ & NORTHSTAR & $\begin{array}{l}\text { We are a new PBRN with a focus on improving rural healthcare in North Dakota } \\
\text { and adjacent areas. We are in the process of starting our first network research } \\
\text { project, and we've encountered some issues with the Institutional Review Board } \\
\text { (IRB). Because we are housed at the University of North Dakota, all of the IRB } \\
\text { issues will be handled through the university's board. In accordance with the } \\
\text { Federal guidelines, the university requires every investigator and research } \\
\text { personnel to go through training on human subjects protection. They provide } \\
\text { online educational modules, but they take approximately } 2-3 \text { hours to complete. } \\
\text { We are concerned that many of our network members will not complete the } \\
\text { training due to the length of the modules and time constraints. }\end{array}$ \\
\hline & & $\begin{array}{l}\text { I am curious to hear about some of the practices your networks have employed in } \\
\text { terms of IRB training. Have any of you been successful in creating and using } \\
\text { some type of modified IRB training? Any suggestions you have would be greatly } \\
\text { appreciated. }\end{array}$ \\
\hline
\end{tabular}

\section{Respondent Name}

\author{
Geoffrey \\ Goldsmith
}

OzarkNet

Anne King

Rowena J. Dolor

Lee Green

$\begin{array}{ll}\text { Debbie Graham } & \begin{array}{c}\text { American } \\ \text { Academy of }\end{array} \\ & \text { Family } \\ & \text { Physicians } \\ \text { National } \\ \text { Research } \\ \text { Network (AAFP } \\ \text { NRN) }\end{array}$

Practice-based

Research

Network

(ORPRN)

Duke Primary Care Research Consortium (PCRC)

Great lakes Into research Network (GRIN)

NRN)
Oregon Rural

\section{Response}

We faced the same issue here, and our work-around has been (whenever possible) to get our study classified as exempt by virtue of it being a quality improvement project instead of research. This also eliminates the need for informed consent for the patients. We pay the site staff and physicians to complete the IRB training.

ORPRN is similar in that we use practice facilitators. Most of the time in our studies, the clinicians and staff are the ones being studied. In other words, their activities are considered "usual care," and we are measuring what happens. In those cases, our IRB doesn't consider them "engaged in research" and so does not require the training. If they are doing activities that are considered research (such as obtaining consent and doing something not considered usual care), then we do have to have them do the training. They hate it, and we try to make it explicit in the contract with them that it's required. We've also started paying them for that hour or so that it takes to complete it.

We ran into a similar issue with the National Children's Study (NCS) Pilot. Although the consent was obtained by our research staff, the community providers had to undergo training because they were collecting study data (ie, filling out the NCS physical exam form).

We had the providers do the minimum number of modules required by the IRB (2 online modules). We also gave them instructions on how to access the Website, and create a login and password. We printed out all the slides and accompanying text so they could refer to these documents when they had to take the online quiz.

Most of our practices in our state-wide network are covered under IRBs other than that of the University of Michigan, which does not have standing to mandate its own human subjects protection course. The staff at each practice must adhere to their own IRB's requirements to satisfy the federal regulation. We've strongly encouraged practices without an existing IRB affiliation to complete a Federalwide Assurance (FWA) (http://www.hhs.gov/ohrp/ humansubjects/assurance/filasurt.htm) with CRIRB, the Community Research IRB at Michigan State University. (GRIN is jointly sponsored by Michigan State University and University of Michigan.)

We have found it acceptable at most places for us to put on a human subjects protection workshop at sites. We go out and bring lunch, and run through the important information with them. (It probably helps that I'm on the IRB here, so I have some credibility with the various other IRBs in teaching our on-site mini-courses.)

The AAFP IRB requires that researchers complete the online CITI (Collaborative Institutional Training Initiative) training. We have worked with the IRB to put together a set of CITI modules that are of importance to our practices that are participating in PBRN studies. We have come to an agreement that there are 5 modules (including the introduction) that are of most importance to the researchers at the practice level. These are the modules that the individuals at the practice level who participate in our research studies are required to complete. It generally takes 1-2 hours to complete these modules.

In addition, with the help of one of our investigators, we have put together a slide presentation that presents all of the information in these 5 modules. The practice can make this presentation in their office, or we can provide paper copies of the presentation if they prefer to use paper. After going through the slide presentation, individuals then complete the CITI quizzes for the appropriate modules and print out their certificates. We are happy to make this slide presentation available to PBRNs that are interested. 
Table 1. Continued

\begin{tabular}{|c|c|}
\hline Inquirer Name & PBRN \\
\hline Paul Smith & $\begin{array}{l}\text { Wisconsin } \\
\text { Research and } \\
\text { Education } \\
\text { Network } \\
\text { (WREN) }\end{array}$ \\
\hline Barry Saver & $\begin{array}{l}\text { UMass Family } \\
\text { Medicine PBRN }\end{array}$ \\
\hline Zsolt Nagykaldi & $\begin{array}{l}\text { Oklahoma } \\
\text { Physicians } \\
\text { Research/Resource } \\
\text { Network } \\
\text { (OKPRN) }\end{array}$ \\
\hline Paul Smith & WREN \\
\hline
\end{tabular}

Chris Landon Pediatric

Diagnostic

Center PBRN

(PDCPBRN)

Jo Demarest

Advanced Practice Registered

Nurse Research

Network

(APRNet)

Cynthia L. Price

Southern Illinois

Practice

Research

Organization

(SIPRO)

Pete Smith
Building

Investigative

practices for

Better Health

Outcomes

(BIGHORN)/

State Networks

of Colorado

Ambulatory

Practices and

Partners

(SNOCAP)
Zolt makes a key point. The most important thing to do is to sit down face-toface with your IRB leaders and talk through what practice-based research is, what sort of minimal risk and exempt projects you plan to do in the future, and how your staff will support the practices and ensure protocol fidelity.

PBRNs are a foreign concept to many IRBs, and educating them is a key to moving forward.

WREN is blessed with a very understanding IRB. We are only required to have human subjects training certification for clinicians or staff who do the subject enrollment for projects that require informed consent. At the moment, they only have to do it once, although there may be a recertification process in the near future.

We also invited a representative from our IRB to conduct training using their slide presentation for a mass training at one of our annual meetings. This was a great way to train a large group at once and might be a way to jump-start your new network.

The NIH (National Institutes of Health) has online human subjects training available, but I do not know how long it takes. Surely your IRB would accept the NIH training.

Don't be too sure about the IRB honoring the NIH training. At my previous institution, they did NOT accept the NIH training, only the University of Miami one. [Editor's note: The University of Miami developed the CITI HSP training modules.] Good enough for NIH, not good enough for the IRB? Go figure.

But please, make sure that your IRB accepts these solutions. Some unfortunately will not accept "outside" resources and curricula as valid for any study run by university personnel (faculty) and/or supported by the university in any way.

It is hard to read this message and the replies on how to get around physicians and nurses learning about ethical research. We have presented it as an opportunity, not a burden.

Documentation of human subjects training is a requirement for membership into APRNet, and, to participate in our research, HIPAA training is also required. It might at first seem as if the training takes too much time, but to conduct studies ethically is most important of all. Everyone who takes the training learns something that they did not know before. The last thing a network needs is for the ethics of its research to be questioned. This is probably not the response you wanted, but in my opinion your network members will just need to bite the bullet and do it.

Southern Illinois University School of Medicine (SIU) located in Springfield, IL, is the academic partner for the Southern Illinois Practice Research Organization (SIPRO), the community health center-based research network of the Southern Illinois Healthcare Foundation (SIHF). The Springfield Committee for Research Involving Human Subjects, SIU's IRB, requires research personnel to take human subjects protection training through CITI. This training consists of 17 educational modules.

Our first SIPRO study will probably have a principal investigator (PI) from SIU with a co-PI from SIHF. Research staff that are considered "key personnel" will be required to take SIU's 17 training modules. When that time comes, I will offer some incentives for providers and staff to complete the training and suggest that the training be done over days or weeks (2-3 modules at a time).

I would also encourage you to go to the DHHS website and review the relevant guiding documents: http://www.hhs.gov/ohrp/policy/index.html.

Most IRBs don't understand what we do, or how what we do fits into the existing Federal directives. We made a point of knowing the regulations inside and out, and therefore were able to negotiate a win-win with our IRB. For example, they were most concerned about our unaffiliated practices (not covered under the regional university-affiliated IRB or under any other local IRBs such as other hospitals). We have since joined our network to our regional not-for-profit AHEC (Area Health Education Center), which is the entity the IRB now deals with-our university rules prohibit us from starting our own 503(c)(3) non-profit organization. The AHEC (under our guidance) ensures compliance and assumes the risk so the IRB doesn't have to worry about problems if they get audited. We still need to train our practices, but as long as AHEC takes on the liability, the IRB doesn't much care how it is done. We use the AAFP National Research Network (NRN) CITI modules. We have it whittled down to about 45 minutes, and either do it at the practices over lunch or at our annual PBRN convocation. 
Table 1. Continued

\begin{tabular}{llc}
\hline Inquirer Name & PBRN & Question \\
\hline
\end{tabular}

Debbie Graham AAFP NRN

Margaret Love

Kentucky
Ambulatory
Network (KAN)

Kentucky Network (KAN)
Every IRB has its own specific requirements—some require NIH training, some require CITI, and some require a specific training put together by the institution. Sometimes you can work with your IRB to modify the requirement. We found that it is critical to create a working relationship with your IRB, keep the lines of communications open, and provide information on PBRN research so that they understand what you do.

I heartily echo the advice others have already provided. At KAN, we've tried to develop a collaborative relationship over time with the Univ. of Kentucky Office of Research Integrity and the Institutional Review Board (IRB) - educating/orienting the IRB leaders about PBRN research and demonstrating that we value the IRB principles, concerns, and oversight.

At KAN's first member meeting in 2000, all attendees participated in a session jointly led by the Chair of the University of Kentucky's IRB and the Director of KAN (Dr. Kevin Pearce). Although the message from the IRB was a little scary sometimes (eg, how much trouble everyone could get into), the forum showed the IRB early on that we (KAN) respected its principles and processes, and we began to expose our community-based PBRN members to the IRB review concepts. That first year, Kevin Pearce and I also met with the IRB Chair to discuss how human subjects protection (HSP) processes and review might play out in KAN. I was astonished to hear potential scenarios of independent IRB review or charging a fee to non-university researchers for IRB review. However, the meeting helped me understand the IRB's perspective and, again, showed the IRB that we wanted to do this right. Later, when we had extramural support for a PBRN consultation, we hosted a workshop about IRB/ HSP issues and practice-based research. The consultant was an expert in IRB and compliance issues for clinical trials at another university. Not only did KAN's faculty and staff attend, but other university researchers and a variety of our university's IRB leaders and staff members participated. It was a great opportunity to involve lots of perspectives in an open discussion about what could work and why and how. I credit our Network Director with the foresight to seek out the IRB.

The education and orientation process did not stop there. Many KAN protocols were discussed extensively with the IRB staff, including its most senior staff members. Although it is best if conversations with IRB staff take place before we submit an IRB application, we have sometimes challenged IRB reviewers' concerns. Also, KAN's research leadership (eg, Senior Research Coordinator, Mary Barron) reviews any KAN-related IRB submissions to make sure principal investigators do not unwittingly set precedents we do not want to live with down the road.

So far, our community-based member clinicians have rarely had to complete HSP training in order to participate in KAN studies. At this point, no HSP training would be acceptable to our university other than the same lengthy training required of full-time university "key personnel" (Dunn \& Chadwick book with on-line testing or CITI on-line modules and testing). So, our KAN research staff does the research, especially the consenting of patients into studies. Having a clinician refer patients to us for possible recruitment and consent is not the same as having the clinician recruit and consent the patient into the study. Also, when possible, KAN clinicians, not patients, are the subjects of the study.

IRB review and HSP education requirements for PBRNs vary widely across institutions; they are challenging everywhere, but not insurmountable. Our Wisconsin colleague in PBRN research, Dr. John Beasley, has often said that IRB issues are an irresistible discussion topic. I think your query is proving him right!

Continued the clinic staff know the patients personally, the risks to patient privacy and confidentiality and the potential threat of coercion are greater when clinic staff are involved than when non-practice research assistants review records. ${ }^{9}$

Physicians and staff participating in practicebased research should be aware of how the
HIPAA Privacy Rule ${ }^{10}$ limits the use and disclosure of PHI for research studies. A business associate agreement is one strategy by which PBRN research assistants can access PHI to identify and recruit eligible study participants in situations where the network clinic staff are not able to provide such assistance to the study. ${ }^{11}$ 


\begin{tabular}{|c|c|c|}
\hline Inquirer Name & PBRN & Question \\
\hline Zsolt Nagykaldi & OKPRN & $\begin{array}{l}\text { In summary, if I may, most networks would probably need a tiered system where } \\
\text { central research personnel (eg, academic faculty, research assistance, practice } \\
\text { facilitators, etc.) would have to eat the whole meal in order to qualify, whereas } \\
\text { "community participants" would have the option of eating only the course(s) } \\
\text { that match the activities they are actually involved with, which is mostly on-site } \\
\text { patient recruitment. A reasonable clinician and staff remuneration for taking the } \\
45 \text { minutes module could be built into the grant proposal. This change alone } \\
\text { could set all PBRNs in the country on a straight path and would actually } \\
\text { improve compliance and cooperation between IRBs and PBRN researchers. } \\
\text { Second, PBRN leader investigators should work with their IRBs on a practice- } \\
\text { based research HSP curriculum, separate from the general basic science/clinical } \\
\text { trials curriculum. Our HSP training, for example, includes an hour just on drug } \\
\text { trials, which none of us (and none of the overwhelming majority of PBRNs) do. } \\
\text { On the other hand, a body of key information pertaining to practice-based } \\
\text { research is completely missing from the curriculum. So, we are teaching the } \\
\text { wrong things to the wrong audience. This doesn't sound like improving } \\
\text { research ethics. If that, too, could be changed (ie, setting up separate modules } \\
\text { for basic, Phase I translational, and Phase II-III translational investigators), we } \\
\text { could be the happiest bunch. }\end{array}$ \\
\hline Pat Fontaine & $\begin{array}{l}\text { Minnesota } \\
\text { Academy of } \\
\text { Family } \\
\text { Physicians } \\
\text { Research } \\
\text { Network } \\
\text { (MAFPRN) }\end{array}$ & $\begin{array}{l}\text { Excellent summary of a good discussion. I think you point the way for future } \\
\text { directions, Zsolt. The IRB training topic is obviously a good one for the } \\
\text { Resource Center to develop, perhaps as a peer learning group session. }\end{array}$ \\
\hline
\end{tabular}

\section{Can HSP Training be Tailored for Community Practices?}

Defining the appropriate level of training for community practices is an important aspect for PBRN researchers to determine when implementing a study protocol. ${ }^{12}$ In general, training modules should cover the ethical principles of research, informed consent, conflicts of interest, the definitions and consequences of research fraud, and HIPAA constraints on using PHI to identify and recruit eligible patients. Additional modules can be required based on the study protocol; for example, records-based research, studies involving children, or working with investigational drugs or devices.

Many IRBs are ill-informed about the types of low-risk research typically conducted by PBRNs, and initiating a dialogue about how a PBRN's research may differ from their IRB's typical portfolio can prevent future difficulties. The PBRN administrative group can then consult with their IRB to discuss appropriate training requirements for community practice staff. Often the requirements can be modified for the specific project or community practitioner role. As stated in the PBRN listserv discussion, the American Academy of Family Physicians National Research Network and IRB selected the appropriate level of training for community practices involved in
PBRN research, thus reducing the usual Collaborative IRB Training Initiative $(\mathrm{CITI})^{13}$ course requirements down to 4 modules. ${ }^{14}$

\section{What Methods are Used for Community Practice HSP Training?}

HSP training should be feasible for community practitioners and their staff to complete. Multiple methods have been used by PBRNs based on their ease and convenience. Online training allows asynchronous learning but requires computer and Internet access. Compact discs, digital video discs, videotapes, and paper copies are easier to disseminate and view. Lectures, with slide presentations conducted at the practice during a study start-up meeting or a regional PBRN meeting, are often used to train many personnel in a quick, efficient fashion. IRBs may require completion of courses by the National Institutes of Health (eg, the Office of Clinical Research Training and Medical Education Clinical Research Training Online ${ }^{15}$ ), the CITI modules, or institution-developed research ethics modules. A paper version of the online module is helpful for providers and staff who prefer paperbased learning or as referral material for those completing online quizzes at the end of each module. Depending on the modality of training chosen 
Table 2. Human Subject Protection Training Resources

\begin{tabular}{|c|c|c|c|}
\hline Title & Website URL & Format & Comments \\
\hline $\begin{array}{l}\text { National Institutes of } \\
\text { Health policy } \\
\text { statement on } \\
\text { "Required Education } \\
\text { in the Protection of } \\
\text { Human Research } \\
\text { Participants" }\end{array}$ & $\begin{array}{l}\text { http://grants.nih.gov/grants/guide/notice- } \\
\text { files/NOT-OD-00 to 039.html }\end{array}$ & Online & $\begin{array}{l}\text { Delineates the policy for key } \\
\text { personnel education in the } \\
\text { protection of human } \\
\text { subjects }\end{array}$ \\
\hline $\begin{array}{l}\text { Protecting Human } \\
\text { Research Participants }\end{array}$ & http://phrp.nihtraining.com & Online & Free \\
\hline $\begin{array}{l}\text { Clinical Research } \\
\text { Training Online } \\
\text { Course for Principal } \\
\text { Investigators }\end{array}$ & $\begin{array}{l}\text { http://www.cc.nih.gov/training/training/ } \\
\text { crt.html }\end{array}$ & Online & $\begin{array}{l}\text { Free; required for NIH } \\
\text { personnel or non-NIH } \\
\text { research staff involved in } \\
\text { NIH clinical contract } \\
\text { projects }\end{array}$ \\
\hline $\begin{array}{l}\text { Collaborative IRB } \\
\text { Training Initiative }\end{array}$ & http://www.citiprogram.org & Online & $\begin{array}{l}\text { Free to learners; institutions } \\
\text { are charged a fee for use } \\
\text { by their faculty/staff. The } \\
\text { modules are updated to } \\
\text { provide the latest } \\
\text { regulatory information } \\
\text { and guidance. The AAFP } \\
\text { NRN has selected } \\
\text { coursework modules for } \\
\text { community practice staff; } \\
\text { other institutions can } \\
\text { contact CITI to do the } \\
\text { same, but these must be } \\
\text { approved by their own } \\
\text { IRB. }\end{array}$ \\
\hline $\begin{array}{l}\text { Institutionally-based } \\
\text { courses }\end{array}$ & $\begin{array}{l}\text { IRB websites contain information about } \\
\text { required training for research } \\
\text { personnel }\end{array}$ & Online, lecture, paper & $\begin{array}{l}\text { Because of the resources } \\
\text { required to continuously } \\
\text { update their courses, } \\
\text { many institutions are } \\
\text { subscribing to the CITI } \\
\text { HSP training modules. }\end{array}$ \\
\hline $\begin{array}{l}\text { Protecting Study } \\
\text { Volunteers by CM } \\
\text { Dunn \& G. Chadwick }\end{array}$ & $\begin{array}{l}\text { http://store.centerwatch.com/p-51- } \\
\text { protecting-study-volunteers-3rd- } \\
\text { edition.aspx }\end{array}$ & $\begin{array}{l}\text { Book; an exam is provided } \\
\text { with each manual and is } \\
\text { available online. }\end{array}$ & $\begin{array}{l}\text { Not geared toward busy } \\
\text { community providers }(7.5 \\
\text { hours of CME or } 9.0 \\
\text { nursing contact hours) }\end{array}$ \\
\hline
\end{tabular}

by the PBRN and IRB, completion can take between 1 and 3 hours (Table 2).

Reimbursement of community-based clinic staff for the time required for HSP training is highly encouraged. Reimbursement to community practices for training should be added to study budgets at proposal submission. Offering continuing medical education or continuing education unit credits for completing HSP training benefits the practice staff who need to maintain training records for state license renewal, hospital credentialing, or specialty certification. Conducting lectures during lunch hours and offering a meal is an efficient method for practice-based training.

\section{Working With Multiple IRBs}

When a PBRN practice membership spans more than one IRB, the requirements from each of the
IRBs should be maintained in some fashion, eg, a database to keep track of each institution's training preference. ${ }^{16}$ Sites that are not affiliated with an IRB should follow the requirements of the IRB that is willing to assume responsibility for their review; unaffiliated investigator agreements often include language that the site will adhere to the policies of the institutional IRB. Some PBRNs formalize these relationships, when possible, by incorporating their network as a not-for-profit entity and covering otherwise unaffiliated practices under a single Federalwide Assurance. Again, opening discussions with the multiple IRBs about the unique nature of PBRNs may result in more streamlined common processes. Regardless, PBRNs should also keep documentation of training completed by community clinicians and staff and know whether annual renewal or recertification is required. 


\section{Conclusion}

The request for advice on the AHRQ PBRN listserv generated a host of responses from PBRN researchers about the methodology and feasibility of community practice HSP training. Most PBRNs had tailored the training requirements for low-risk PBRN research (eg, surveys, practice improvement, or behavioral interventions) conducted in real-world, non-academic practices. A variety of methods-online, paper, or lecture-are offered to make training easy to complete. Reimbursement for time spent on training is recommended, as well as a discussion with the institutional IRB(s) within a PBRN to define the acceptable strategies for training community-based staff in the areas of HSP most germane to their research involvement.

The authors would like to thank Amanda McMillan for her editorial assistance.

\section{References}

1. Love MM, Pearce KA, Williamson MA, Barron MA, Shelton BJ. Patients, practices, and relationships: challenges and lessons learned from the Kentucky Ambulatory Network (KAN) CaRESS Clinical Trial. J Am Board Fam Med 2006;19:75-84.

2. Agency for Healthcare Research and Quality. Primary care practice-based research networks (homepage). Available from http://pbrn.ahrq.gov. Accessed 20 May 2008.

3. Christensen CM, Raynor ME. The innovator's solution. Boston (MA): Harvard Business School Press; 2003.

4. Westfall JM, Mold JW, Fagnan L. Practice-based research: 'blue highways' on the NIH Roadmap. JAMA 2007;297:403-6.

5. Mold JW, Peterson KA. Primary care practice-based research networks: working at the interface between research and quality improvement. Ann Fam Med 2005;3(Suppl 1):S12-20.
6. Miller FG, Emanuel EJ. Quality-improvement research and informed consent. N Engl J Med 2008; 358:765-7.

7. US Department of Health and Human Services. Office for Human Research Protections (homepage). Available from http://www.hhs.gov/ohrp. Accessed 25 April 2008.

8. Graham DG, Spano MS, Stewart TV, Staton EW, Meers A, Pace WD. Strategies for planning and launching PBRN research studies: a project of the Academy of Family Physicians National Research Network (AAFP NRN). J Am Board Fam Med 2007; 20:220-8.

9. Wolf LE, Croughan M, Lo B. The challenges of IRB review and human subjects projections in practicebased research. Med Care 2002;40:521-9.

10. US Department of Health and Human Services. Office for Civil Rights-HIPAA. Medical privacynational standards to protect the privacy of personal health information. Available from http://www.hhs. gov/ocr/hipaa/finalreg.html. Accessed 1 May 2008.

11. Neale AV, Schwartz KL. A primer of the HIPAA Privacy Rule for practice-based researchers. J Am Board Fam Pract 2004;17:461-5.

12. Wolf LE, Walden JF, Lo B. Human subjects issues and IRB review in practice-based research. Ann Fam Med 2005;3:S30-7.

13. Graham DG, Spano MS, Manning B. The IRB challenge for practice-based research: strategies for the American Academy of Family Physicians National Research Network (AAFP NRN). J Am Board Fam Med 2007;20:181-7.

14. Collaborative Institutional Training Initiative. CITI login and registration page. Available from http:// www.citiprogram.org/. Accessed 20 May 2008.

15. National Institutes of Health Clinical Center, Office of Clinical Research Training and Medical Education. Clinical research training on-line. Available from http://www.cc.nih.gov/training/training/crt.html. Accessed 20 May 2008.

16. Green LA, White LL, Barry HC, Nease DE Jr, Hudson BL. Infrastructure requirements for practice-based research networks. Ann Fam Med 2005; 3(Suppl 1):S5-11. 